\title{
TINGKAT ADOPSI INOVASI POLA TANAM JAJAR LEGOWO PADA BUDIDAYA PADI SAWAH DI DESA BABAKANSARI KECAMATAN SUKALUYU KABUPATEN CIANJUR
}

\author{
Oleh : \\ Ahmad Nur Rizal*) \\ Neni Nurfuadah**)
}

\begin{abstract}
Abstrak
Adanya upaya dari pemerintah untuk meningkatkan produksi padi nasional baik melalui intensifikasi maupun ekstensifikasi pertanian, salah satu teknologi yang diterapkan adalah Jajar Legowo. Cianjur menjadi salah satu kabupaten yang menerapkan jajar legowo melalui kegiatan penyuluhan pada tahun 2012. Tahun 2018 jumlah petani yang menerapkan jajar legowo mengalami peningkatan. Perlu diketahui seberapa besar tingkat adopsi teknologi jajar legowo di Cianjur khususnya di Desa Babakan Sari Kecamatan Sukaluyu. Penelitian ini dilaksanakan di Desa Babakan Sari, Kecamatan Sukaluyu, Kabupaten Cianjur. Penentuan lokasi dilakukan secara purposive karena didesa tersebut terdapat kelompok tani yang menerapkan budidaya padi dengan sistem tanam jajar Legowo. Metode analisis data dalam peneltian ini adalah analisis deskriptif. Hasil penelitian diperoleh bahwa; Karakteristik petani yaitu; mayoritas berumur $>39$ tahun, pengalaman bertani lebih dari $>20$ tahun kemudian tingkat pendidikan SD, tingkat penghasilan petani $<3$ juta, luas lahan yang digarap kurang dari $0,5 \mathrm{Ha}$ dan tanggungan keluarga mencapai 4 orang. Kemudian tingkat adopsi inovasi pola tanam jajar Legowo pada budidaya padi sawah di Desa Babakansari, Kecamatan Sukaluyu, Kabupaten Cianjur termasuk pada tingkat Adopsi Tinggi, yaitu 79,80\% dan kendala yang dihadapi petani padi sawah dalam mengadopsi sistem tanam jajar Legowo di Desa Babakansari adalah kurangnya motivasi petani dalam mengikuti pelatihan yang diberikan oleh petugas penyuluh lapangan terkait dengan penerapan jajar legowo dan sulitnya mencari tenaga kerja karena terserap oleh pabrik-pabrik.
\end{abstract}

Kata Kunci: Adopsi Inovasi, Jajar Legowo.

\begin{abstract}
There is an effort from the government to increase national rice production both through intensification and agricultural extensification, one of the technologies applied is Jajar Legowo. Cianjur became one of the districts that implemented legowo ranks through counseling activities in 2012. In 2018 the number of farmers who applied legowo ranks increased. It is important to know how much the adoption rate of jajar legowo technology in Cianjur, especially in Babakan Sari Village, Sukaluyu District. This research was carried out in Babakan Sari Village, Sukaluyu District, Cianjur Regency. Determination of the location is done purposively because in the village there are farmer groups that apply rice cultivation with the Legowo row planting system. Data analysis method in this research is descriptive analysis. The research results obtained that; The characteristics of farmers, namely; the majority are $>39$ years old, farming experience more than $>20$ years later elementary school education level, farmer income level $<3$ million, the area of land under cultivation is less than $0.5 \mathrm{Ha}$ and family dependents reach 4 people. Then the adoption rate of innovation of Legowo row planting patterns in lowland rice cultivation in Babakansari Village, Sukaluyu Subdistrict, Cianjur Regency is included in the High Adoption rate, which is $79.80 \%$ and the obstacles faced by lowland rice farmers in adopting the Legowo row planting system in Babakansari Village
\end{abstract}


are the lack of the motivation of farmers to take part in the training given by the field extension officers is related to the application of jajar legowo and the difficulty in finding workers because they are absorbed by factories.

Keywords: Adoption of Innovation, Jajar Legowo.

*) Alumni Fakultas Sains Terapan UNSUR

**) Dosen Fakultas Sains Terapan UNSUR 


\section{PENDAHULUAN}

Pemahaman terhadap teknologi tanam jajar Legowo padi menjadi penting agar manfaat yang akan diperoleh dari penerapannya akan lebih optimal.

Salah satu wilayah yang sudah menerapkan teknologi jajar Legowo adalah Desa Babakan Sari Kecamatan Sukaluyu Kabupaten Cianjur, dengan harapan dapat meningkatkan produksi dan produktivitas tanaman padi. Akan tetapi hal tersebut tidak mungkin dapat dilakukan jika peran serta dari penyuluh pertanian yang memberikan transfer ilmu dan teknologi terhadap petani tidak dilakukan secara optimal.

Berdasarkan beberapa fenomena tersebut, maka perlu diketahui bagaimana tingkat adopsi inovasi pola tanam jajar Legowo pada budidaya padi sawah di Desa Babakansari, Kecamatan Sukaluyu, Kabupaten Cianjur, sehingga dapat dijadikan standar acuan untuk lebih ditingkatkan. Selain itu, perlu diketahui beberapa faktor yang menjadi kendala bagi petani dalam menerapkan teknologi tanam Jajar Legowo di Desa Babakansari, Kecamatan Sukaluyu, Kabupaten Cianjur.

Tujuan dari pelaksanaan penelitian di Desa Babakansari, Kecamatan Sukaluyu, Kabupaten Cianjur adalah sebagai berikut:

1. Mengetahui karakteristik petani padi sawah di Desa Babakansari, Kecamatan Sukaluyu, Kabupaten Cianjur.

2. Mengetahui tingkat adopsi inovasi pola tanam jajar Legowo pada budidaya padi sawah di Desa Babakansari, Kecamatan Sukaluyu, Kabupaten Cianjur.

3. Menganalisis kendala yang dihadapi petani padi sawah dalam mengadopsi sistem tanam jajar Legowo di Desa Babakansari, Kecamatan Sukaluyu, Kabupaten Cianjur.

(2011) mengartikan adopsi sebagai penerapan atau penggunaan sesuatu ide, alat-alat atau teknologi baru yang disampaikan berupa pesan komunikasi (lewat penyuluhan). Manifestasi dari bentuk adopsi ini dapat dilihat atau diamati berupa tingkah laku, metoda, maupun peralatan dan teknologi yang dipergunakan dalam kegiatan komunikasinya.

Menurut Ginting (2014), proses penerimaan inovasi terdapat 5 (lima) tahapan, yaitu :

1. Sadar,

2. Minat,

3. Penilaian,

4. Mencoba

5. Adopsi atau menerapkan

Legowo menurut bahasa Jawa berasal dari kata "Lego" yang berarti luas dan "dowo" yang berarti panjang. Pada prinsipnya sistem tanam jajar Legowo adalah meningkatkan populasi dengan cara mengatur jarak tanam.

Balai Pengkajian dan Pengembangan Teknologi Pertanian (2009) bahwa cara tanam jajar Legowo 2:1 adalah cara tanam berselang-seling dua baris dan satu baris dikosongkan.

$$
\text { Menurut Ginting }
$$

Karakteristik petani adalah ciri-ciri yang melekat pada individu petani yang dapat membedakannya dengan petani lainnya yang dapat mempengaruhi dalam proses penerapan teknologi baru.

Menurut Ginting (2014) adopsi teknologi baru adalah merupakan proses yang terjadi dari petani untuk menerapkan teknologi tersebut pada usaha taninya.

1. Umur petani

2. Pengalaman bertani

3. Tingkat pendidikan petani

4. Total pendapatan

5. Luas pemilikan lahan

6. Jumlah Tanggungan

Hasil penelitian dari Septiana, dkk (2016) berdasarkan hasil penelitian terhadap 35 orang petani Kelompok Tani Sekar Arum mengenai tingkat adopsi sistem tanam jajar legowo dengan menggunakan metode skoring (likert) menunjukkan bahwa tingkat adopsi sistem 
tanam jajar legowo pada usahatani padi sawah yang dikategorikan tinggi sebesar $17,1 \%$ yaitu sebanyak 6 orang petani, kategori sedang sebesar $80 \%$ yaitu sebanyak 28 orang petani dan kategori rendah sebesar $2,9 \%$ yaitu 1 orang petani. Sementara berdasarkan hasil uji regresi logistik menyimpulkan bahwa variabel tingkat pendidikan berpengaruh secara nyata terhadap tingkat adopsi sistem tanam jajar legowo. Sementara variabel lain tidak berpengaruh secara nyata karena memiliki tingkat signifikansi lebih dari 0,05 .

Hasil penelitian dari Rizki (2017) diperoleh hasil bahwa partisipasi petani dalam program tanam Jajar Legowo pada kategori tinggi yang berarti dengan adanya kesadaran dan pemahaman petani yang tinggi mengenai program tersebut akan mendorong partisipasi yang tinggi dalam penerapan inovasi tersebut.

Hasil penelitian dari Rebekka, dkk (2018) diperoleh hasil bahwa perlakuan sistem tanam Jajar Legowo nyata meningkatkan produksi padi sawah dimana pada sistem tanam jajar legowo 4:1 (L2) lebih tinggi yaitu 10,2 ton/ $\mathrm{Ha}$ dibandingkan dengan sistem tanam jajar legowo 2:1 (L1) yaitu hanya 8,9 ton / ha dan sistem tanam kontrol (L0) yaitu 8,5 ton/ ha. Pada perlakuan varietas berpengaruh tidak nyata meningkatkan pertumbuhan dan produksi padi sawah. Interaksi sistem tanam dan varietas berpengaruh tidak nyata terhadap pertumbuhan dan produksi padi sawah, yang optimal dianjurkan menggunakan sistem tanam jajar legowo 4:1.

\section{METODE PENELITIAN}

Penelitian ini akan dilaksanakan di Desa Babakansari, Kecamatan Sukaluyu, Kabupaten Cianjur. Penentuan lokasi dilakukan secara purposive karena didesa tersebut terdapat kelompok tani yang menerapkan padi dengan sistem tanam jajar Legowo. Waktu penelitian akan dilaksanakan pada bulan Mei sampai dengan Juli 2019.
Penelitian ini termasuk pada penelitian deskriptif. Dimana Sampel dalam penelitian ini adalah petani yang sudah menerapkan inovasi Jajar Legowo pada budidaya padi sawah di Desa Babakansari, Kecamatan Sukaluyu, Kabupaten Cianjur, dimana jumlah sampel sebanyak 33 orang. Teknik penarikan sampel dalam penelitian ini menggunakan teknik Sensus artinya semua populasi dijadikan sampel penelitian (Sugiyono, 2013).

Metode analisis data dalam peneltian ini adalah analisis deskriptif. Menurut Sugiyono (2013), analisis deskriptif adalah analisis yang mendeskripsikan atau memberi gambaran terhadap obyek yang diteliti melalui data sampel atau populasi sebagaimana adanya, tanpa membuat kesimpulan yang berlaku untuk umum.

Analisis tingkat adopsi dilakukan dengan formula sebagai berikut:

$$
T A=\frac{N F}{T} \times 100 \%
$$

$$
\begin{aligned}
\mathrm{TA}= & \text { Tingkat adopsi (persentase) } \\
\mathrm{NF}= & \text { Nilai faktor hasil pengamatan } \\
& \text { adopsi di lapangan (unit adopsi) } \\
\mathrm{T}= & \text { Total komponen/aspek teknologi } \\
& \text { yang dianjurkan (unit) }
\end{aligned}
$$

Klasifikasi tingkat adopsi

(ditetapkan berdasarkan expert judgment)

$0-44,99 \%=$ Klasifikasi adopsi rendah

$45-\quad 64,99 \%=$ Klasifikasi adopsi sedang

$65-100 \%=$ Klasifikasi adopsi tinggi

Berdasarkan pendapat tersebut, peneliti tidak melakukan kesimpulan secara umum tentang tingkat adopsi inovasi pola tanam jajar legowo pada budidaya padi sawah di Desa Babakansari Kecamatan Sukaluyu Kabupaten Cianjur. 


\section{HASIL DAN PEMBAHASAN}

Karakteristik petani memiliki sifat yang unik dan berbeda antara petani yang satu dengan petani lainnya. Karakteristik petani yang akan dilihat dalam penelitian ini dibedakan menjadi enam, yaitu: umur, pengalaman bertani, tingkat pendidikan, total pendapatan, luas kepemilikan lahan dan jumlah tanggungan keluarga.

Tabel1. Karakteristik Petani Ber-dasarkan Umur.

\begin{tabular}{cccc}
\hline No & Umur & Jumlah & Persentase \\
\hline 1 & $<20$ Tahun & 0 & - \\
2 & $20-29$ Tahun & 2 & 6,06 \\
3 & 30-39 Tahun & 5 & 15,15 \\
4 & $>$ 39 Tahun & 26 & 78,79 \\
\hline & Total & $\mathbf{3 3}$ & $\mathbf{1 0 0 , 0 0}$ \\
\hline
\end{tabular}

Sumber: Hasil olah data, 2019.

Tabel 1. menyajikan data persentase petani menurut kelompok usia. Sebagian besar petani $(78,79 \%)$ berada pada kategori usia $>39$ Tahun, petani usia lebih dari $>39$ tahun tampak lebih aktif dalam mencari informasi mengenai teknologi jajar legowo pada budidaya padi sawah di Desa Babakansari Kecamatan Sukaluyu Kabupaten Cianjur.

Berikut adalah karakteristik petani berdasarkan pengalaman bertani.

Tabel 2. Karakteristik Petani Ber-dasarkan Pengalaman Ber-tani.

\begin{tabular}{clcc}
\hline No & Pengalaman Bertani & Jumlah & Persentase \\
\hline 1 & $<5$ Tahun & 0 & - \\
2 & 5-10 Tahun & 0 & - \\
3 & 11-20 Tahun & 9 & 27,27 \\
4 & $>20$ Tahun & 24 & 72,73 \\
\hline & Total & $\mathbf{3 3}$ & $\mathbf{1 0 0 , 0 0}$ \\
\hline
\end{tabular}

Sumber: Hasil olah data, 2019.

Tabel 2 dapat diketahui bahwa mayoritas adalah sudah berpengalaman $>$ 20 tahun bertani yang mencapai $72,73 \%$ artinya mayoritas petani di Desa Babakansari sudah berpengalaman sebagai petani. Hal ini dikarenakan sebagian besar petani di Desa Babakansari berprofesi petani sejak kecil akan tetapi ada sebagai kecil yang beralih profesi yang sebelumnya bekerja sebagai PNS, TNI, buruh dan sebagainya menjadi petani.

Berikut adalah karakteristik petani berdasarkan tingkat pendidikan.

Tabel 3. Karakteristik Petani Ber-dasarkan Tingkat Pendidikan.

\begin{tabular}{clccc}
\hline No & Tingkat Pendidikan & Jumlah & Persentase \\
\hline 1 & SD & 17 & 51,52 \\
2 & SMP & 8 & 24,24 \\
3 & SMA & 6 & 18,18 \\
4 & Sarjana & 2 & 6,06 \\
\hline \multicolumn{2}{r}{ Total } & $\mathbf{3 3}$ & $\mathbf{1 0 0 , 0 0}$ \\
\hline
\end{tabular}

Sumber: Hasil olah data, 2019.

Tabel 3. menyajikan data persentase petani menurut tingkat pendidikan formal. Dari total petani, sebagian besar berada pada kategori tingkat pendidikan formal rendah yaitu hanya SD yang mencapai 51,52\%,

sedangkan 6,06\% petani berada pada kategori tingkat pendidikan formal tinggi yaitu sarjana.

Berikut adalah karakteristik petani berdasarkan total pendapatan 
Tabel 4. Karakteristik Petani Ber-dasarkan Total Pendapatan.

\begin{tabular}{clcc}
\hline No & \multicolumn{1}{c}{ Total Pendapatan } & Jumlah & Persentase \\
\hline 1 & <3 Juta & 25 & 75,76 \\
2 & 3-6 Juta & 8 & 24,24 \\
3 & 6-10 Juta & 0 & - \\
4 & >10 Juta & 0 & - \\
\hline \multicolumn{2}{r}{ Total } & $\mathbf{3 3}$ & $\mathbf{1 0 0 , 0 0}$ \\
\hline
\end{tabular}

Sumber: Hasil olah data, 2019.

Berdasarkan data tersebut diketahui bahwa dalam setiap bulan petani memiliki pendapatan kurang dari 3 juta rupiah $75,76 \%$. Adapun petani yang memiliki pendapatan tinggi yang mencapai 3-6 juta rupiah 24,24\%. Hal tesebut disebabkan oleh beberapa faktor berikut ini: (1) petani memiliki pekerjaan sampingan, selain usaha tanaman padi sawah; (2) petani memiliki pabrik padi dan memiliki jaringan pemasaran usaha tanaman padi sawah yang luas ke berbagai daerah.

Selain itu, tinggi rendahnya pendapat petani juga berkaitan dengan luas kepemilikan lahan yang tercantum pada Tabel 5 berikut.

Tabel 5. Karakteristik Petani Ber-dasarkan Luas Kepemilikan Lahan.

\begin{tabular}{clccc}
\hline No & \multicolumn{1}{c}{ Luas Kepemilikan Lahan } & Jumlah & Persentase \\
\hline 1 & $<0,5 \mathrm{Ha}$ & 21 & 63,64 \\
2 & $0,5-1 \mathrm{Ha}$ & 8 & 24,24 \\
3 & $1-3 \mathrm{Ha}$ & 3 & 9,09 \\
4 & $>3 \mathrm{Ha}$ & 1 & 3,03 \\
\hline \multicolumn{2}{r}{ Total } & $\mathbf{3 3}$ & $\mathbf{1 0 0 , 0 0}$ \\
\hline
\end{tabular}

Sumber: Hasil olah data, 2019.

Tabel 5. menunjukkan sebagian luas lahan yang digarap atau diusahan oleh petani adalah lahan yang sempit yaitu $<0,5$ Ha. Hal ini dikarenakan sawah yang dimiliki oleh petani adalah warisan dari orang tua. Kemudian mayoritas petani lahannya diperoleh dari hasil sewa kelola/ gadai.

Jumlah tanggungan keluarga dari petani responden yang dapat dilihat pada Tabel 6 di bawah ini.

Tabel 6. Karakteristik Petani Ber-dasarkan Jumlah Tanggungan Keluarga.

\begin{tabular}{llcc}
\hline No & Jumlah Tanggungan Keluarga & Jumlah & Persentase \\
\hline 1 & 1 orang & 1 & 3,03 \\
2 & 2 orang & 4 & 12,12 \\
3 & 3 orang & 13 & 39,39 \\
4 & $>3$ orang & 15 & 45,45 \\
\hline \multicolumn{2}{c}{ Total } & $\mathbf{3 3}$ & $\mathbf{1 0 0 , 0 0}$ \\
\hline
\end{tabular}

Sumber: Hasil olah data, 2019.

Jumlah tanggungan keluarga adalah banyaknya anggota keluarga yang terdiri dari istri dan anak, serta orang lain yang turut serta dalam keluarga yang hidup dalam satu rumah dan makan bersama yang menjadi tanggungan kepala keluarga. Berdasarkan data tersebut, diketahui bahwa mayoritas responden memiliki tanggungan keluarga lebih dari 3 orang yang mencapai $45,45 \%$. 
Tabel 7. Rekapitulasi Tingkat Adopsi Pola Tanam Jajar Legowo.

\begin{tabular}{clc}
\hline No & \multicolumn{1}{c}{ Standar } & Tingkat Adopsi \\
\hline 1 & Pengolahan Lahan & 84,85 \\
2 & Pembuatan Baris Tanam & 72,73 \\
3 & Penanaman & 66,67 \\
4 & Pemupukan & 84,85 \\
5 & Penyiangan & 93,94 \\
6 & Pengendalian hama dan penyakit & 75,76 \\
\hline \multicolumn{2}{r}{ Rata-rata (\%) } \\
\hline & Tingkat Adopsi Pola & $\mathbf{7 9 , 8 0}$ \\
\hline
\end{tabular}

Sumber: Hasil olah data, 2019.

Berdasarkan tabel tersebut dapat diketahui bahwa rata-rata adopsi inovasi mengenai sistem tanam Jajar Legowo pada responden adalah 79,80\% dan termasuk pada adopsi tinggi. Dimana yang paling tinggi adalah megenai adopsi penyiangan.
Hasil rata-rata tersebut didukung oleh pelaksanaan metode kunjungan sebenarnya lebih banyak dimanfaatkan oleh penyuluh untuk berdiskusi atau berdialog mengenai hal-hal yang berkaitan dengan permasalahan petani dalam berusahatani khususnya mengenai sistem tanam jajar legowo.

Tabel 8. Kendala yang Dihadapi Petani Padi Sawah dalam Mengadopsi Sistem Tanam Jajar Legowo

\begin{tabular}{|c|c|c|c|c|c|}
\hline \multirow{3}{*}{ No } & \multirow{3}{*}{ Pernyataan } & \multicolumn{4}{|c|}{ Jawaban } \\
\hline & & \multicolumn{2}{|c|}{$Y \mathbf{a}$} & \multicolumn{2}{|c|}{ Tidak } \\
\hline & & Jumlah & $\%$ & Jumlah & $\%$ \\
\hline 1 & $\begin{array}{l}\text { Saya kurang memahami sistem } \\
\text { tanam Jajax Legowo yang } \\
\text { dijelaskan oleh penyuluh. }\end{array}$ & 10 & 30,30 & 23 & 69,70 \\
\hline 2 & $\begin{array}{l}\text { Saya jarang mengikuti pelatihan } \\
\text { tentang sistem tanam Jajar } \\
\text { Legowo yang diadakan oleh } \\
\text { penyuluh. }\end{array}$ & 6 & 18,18 & 27 & 81,82 \\
\hline 3 & $\begin{array}{l}\text { Saya kesulitan mencari tenaga } \\
\text { kerja untuk tanam dengan } \\
\text { menggunakan sistem tanam Jajar } \\
\text { Legowo }\end{array}$ & 5 & 15,15 & 28 & 84,85 \\
\hline 4 & $\begin{array}{l}\text { Saya belum memiliki caplak yang } \\
\text { sesuai dengan sistem tanam Jajar } \\
\text { Legowo }\end{array}$ & 4 & 12,12 & 29 & 87,88 \\
\hline 5 & $\begin{array}{l}\text { Saya memiliki kendala dalam } \\
\text { penyiangan jika menggunakan } \\
\text { sistem tanam Jajar Legowo }\end{array}$ & 3 & 9,09 & 30 & 90,91 \\
\hline 6 & $\begin{array}{l}\text { Saya memiliki kendala dalam } \\
\text { pemupukan jika menggunakan } \\
\text { sistem tanam Jajar Legowo }\end{array}$ & 2 & 6,06 & 31 & 93,94 \\
\hline 7 & $\begin{array}{l}\text { Saya memiliki kendala dalam } \\
\text { penanganan hama jika } \\
\text { menggunakan sistem tanam Jajar } \\
\text { Legowo }\end{array}$ & o & $\mathrm{O}, \mathrm{OO}$ & 33 & 100,00 \\
\hline 8 & $\begin{array}{l}\text { Saya memiliki kendala dalam } \\
\text { penanganan penyakit jika } \\
\text { menggunakan sistem tanam Jajar } \\
\text { Legowo }\end{array}$ & 1 & 3,03 & 32 & 96,97 \\
\hline 9 & $\begin{array}{l}\text { Saya memiliki kendala dalam } \\
\text { melakukan } \\
\text { menggunakan sistem tanam Jajax } \\
\text { Legowo }\end{array}$ & 2 & 6,06 & 31 & 93,94 \\
\hline
\end{tabular}

Secara lebih jelas dapat diuraikan beberapa kendala sebagai berikut:

1. Berkaitan dengan kurang memahami tentang sistem tanam jajar Legowo yang dijelaskan oleh petugas penyuluh pertanian, ada 10 orang responden kurang memahami dan mayoritas 23 orang responden memahami. Hal ini menunjukkan bahwa ada peningkatan pengetahuan dan keterampilan petani setelah diberikan penyuluhan oleh petugas penyuluh pertanian yang berkaitan dengan sistem tanam Jajar Legowo.

2. Berkaitan dengan ikut serta responden berkaitan dengan pelatihan sistem 
tanam Jajar Legowo yang diadakan oleh penyuluh dimana ada 6 orang menjawab masih ada kendala dan mayoritas tidak. Seperti diketahui bahwa Penyuluhan pertanian merupakan upaya yang dilakukan dalam rangka meningkatkan kemampuan petani baik pengetahuan sikap dan keterampilan sehingga mereka mampu dan berdaya serta menetapkan keputusan sendiri terkait dengan usaha tani yang dilaksanakannya. Salahsatu kegiatan yang dilakukan dalam penyuluhan adalah mengadakan pelatihan teknis bagi petani. Kegiatan tersebut bertujuan agar petani belajar dengan melibatkan seluruh panca inderanya, dengan harapan mau dan mampu mengadopsi suatu teknologi untuk kemajuan dan perubahan usaha taninya.

3. Kesulitan mencari tenaga kerja untuk tanam dengan menggunakan sistem tanam Jajar Legowo menurut 5 orang masih menjadi kendala sedangkan mayoritas yaitu 28 orang tidak menjadi kendala. Hal tersebut dapat dijelaskan bahwa jika pertama kali tenaga kerja untuk tanam dengan sistem jajar legowo sangat kesulitan, akan tetapi seiring dengan seringnya melakukan penanaman jajar legowo jadi tidak menjadi kendala lagi.

4. Belum memiliki caplak yang sesuai dengan sistem tanam Jajar Legowo tidak menjadi kendala utama dalam penerapan adopsi inovasi jajar legowo karena caplak ada yang diberikan bantuan oleh pemerintah ada yang melakukan modifikasi sendiri agar sesuai dengan lahan sawahnya.

5. Kendala dalam penyiangan jika menggunakan sistem tanam Jajar Legowo tidak menjadi kendala karena mayoritas responden menjawab sudah mengadopsi teknik tanam jajar legowo, umumnya responden berpendapat dengan adanya jajar legowo memudahkan melakukan penyiangan disela-sela tanaman padi tersebut.
6. Kendala dalam pemupukan jika menggunakan sistem tanam Jajar Legowo tidak menjadi kendala karena mayoritas responden menjawab sudah mengadopsi teknik tanam jajar legowo, umumnya responden berpendapat dengan adanya jajar legowo memudahkan melakukan pemupukan disela-sela tanaman padi tersebut.

7. Kendala dalam penanganan hama jika menggunakan sistem tanam Jajar Legowo, dengan menggunakan teknik jajar legowo memudahkan pemantauan hama tanaman padi.

8. Kendala dalam penanganan penyakit jika menggunakan sistem tanam Jajar Legowo dengan menggunakan teknik jajar legowo memudahkan pemantauan penyakit tanaman padi.

9. Kendala dalam melakukan panen jika menggunakan sistem tanam Jajar Legowo, tidak jauh berbeda antara panen menggunakan sistem konvensional dengan sistem tanam jajar legowo sehingga menurut responden tidak menjadi kendala.

\section{KESIMPULAN}

Hasil penelitian yang telah dibahas di bab sebelumnya, dapat disimpulkan beberapa hal sebagai berikut:

1. Karakteristik petani yaitu; mayoritas berumur $>39$ tahun, pengalaman bertani lebih dari $>20$ tahun kemudian tingkat pendidikan SD, tingkat penghasilan petani $<3$ juta, luas lahan yang digarap kurang dari $0,5 \mathrm{Ha}$ dan tanggungan keluarga mencapai 4 orang.

2. Tingkat adopsi inovasi pola tanam jajar Legowo pada budidaya padi sawah di Desa Babakansari, Kecamatan Sukaluyu, Kabupaten Cianjur termasuk pada tingkat Adopsi Tinggi, yaitu $79,80 \%$

3. Kendala yang dihadapi petani padi sawah dalam mengadopsi sistem tanam jajar Legowo di Desa Babakansari adalah kurangnya motivasi petani dalam mengikuti pelatihan yang 
diberikan oleh petugas penyuluh lapangan terkait dengan penerapan jajar legowo dan sulitnya mencari tenaga kerja karena terserap oleh pabrik-pabrik.

\section{DAFTAR PUSTAKA}

Azwar. 2011. Sikap Manusia, Teori dan Pengukurannya. Yogyakarta: Pustaka Pelajar.

Balai Pengkajian dan Pengembangan Teknologi Pertanian. 2009. Sistem Tanam Jajar Legowo. BPPTP: Bandung.

Bappeda. 2018. Laporan Kinerja Bappeda. Cianjur: Bappeda.

BPTP. 2010. Alternatif Teknologi Peningkatan Produksi Beras Nasional. Iptek.

Ginting. 2014. Mengukur tingkat adopsi petani. Jakarta: CV. Rajawali.

Haerurah dan Purwanto. 2011. Budidaya Tanaman Padi. Bandung: PT Remaja Rosdakarya.

Isran Noor. 2012. Buku Pintar Penyuluh Pertanian. Jakarta: PERHIPTANI.

Junaidi. 2014. Komunikasi Massa Pengantar Teoritis. Yogyakarta: Santusta.

Mardikanto dan Sutarni. 2011. Petunjuk Penyuluban Pertanian. Usaha Nasional: Surabaya.

Mardikanto. 2009. Penyuluban Pembangunan Kehutanan. Jakarta: Kementrian Pertanian.

Nasir. 2014. Menggerakekan dan Membangun Pertanian. Jakarta: Yasaguna.

Nurhadi. 2018. Pendekatan kontekstual. Jakarta : PT. Rineka Cipta.

Permana, 1995. Penerapan Adopsi pada Kelompok Tani. Yogyakarta: Pustaka Pelajar.

Pujaratno. 2010. Budidaya Tanaman Padi. Yogyakarta: Pustaka Pelajar.

Purwono dan Heni Purnamawati. 2007. Budidaya dan Jenis Tanaman Pangan Unggul. Jakarta: Penebar Swadaya.

Pusat Penyuluhan Pertanian, 2012. Panduan Pengembangan Kelompok
Tani. Jakarta: Kementrian Pertanian.

Rebekka, dkk. 2018. Pengaruh Sistem Tanam Jajar Legowo Terbadap Pertumbuban dan Produksi Beberapa V arietas Padi Sawah (Oryza sativa L.). Jurnal Agroekoteknologi FP USU: EISSN No. 2337- 6597.

Rizki. 2017. Prinsip Dasar Komunikasi Pertanian. UIP Pres.

Rogers. 1983. Masyarakat Petani dan Kebudayaan. CV Rajawali, Jakarta

Samsudin. 2010. Dasar-Dasar Penyuluhan dan Modernisasi Pertanian. Binacipta: Bandung.

Septiana, dkk. 2016. Tingkat Adopsi Inovasi Sistem Tanam Jajar Legowo Di Kelompok Tani Sedyo Mukti Desa Pendowoharjo Kecamatan Sewon Kabupaten Bantul. Jurusan Agribisnis Fakultas Pertanian UMY.

Soekanto. 2010. Sosiologi Suatu Pengantar. Jakarta: Rajawali Pers

Sugiyono. 2011. Statistik untuk Penelitian. Bandung: Alfabeta.

Suharno. 2013. Dasar-Dasar Teknologi Pengolahan Air Limbah. Gosyen Publishing. Sleman, Yogyakarta

Suparyono dan A.Setyono .1993. Padi. Penebar Swadaya: Jakarta.

Suprapto. 2009. Komunikasi Organisasi, Jakarta :Edisi V. Cetakan ketujuh.

Syahyuti, 2013. Lembaga dan Organisasi petani dalam pengaruh Negara dan Pasar. Majalah Forum Agro Ekonomi Vol. 28 No.1.

Trimo. 2006. Evaluasi Penyuluhan Pembangunan Pertanian. Surakarta: UNS Press.

Umar. 2007. Riset Pemasaran dan Perilaku Konsumen, Jakarta: Penerbit PT. Gramedia Pustaka Utama.

Undang-Undang Nomor 16 tahun 2006 tentang Sistem Penyuluhan Pertanian, Perikanan dan Kehutanan (SP3K). Jakarta: Kementrian Pertanian.

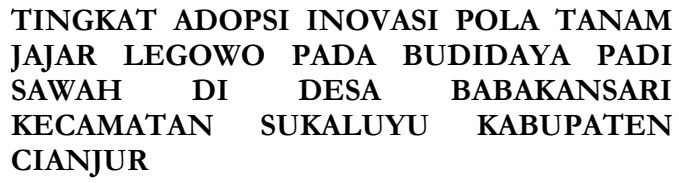

